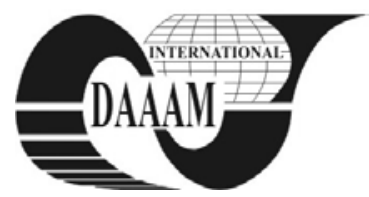

\title{
NEW RESEARCHES REGARDING RELATIONSHIP BETWEEN ELEMENTARY GEOMETRIC SHAPES AND BASIC COLOURS
}

\author{
DUMITRESCU, A[ndrei]
}

\begin{abstract}
Kandinsky's theory about shape-colour correlation stipulates that the best colour for circle is blue, for triangle yellow and for square - red. His hypothesis was based on an experiment carried-out at Bauhaus. Because the original experiment was doubtful and the following ones were inconclusive, the author organised a new experiment.

The experiment was based on the assessment the appropriateness of shape-colour combination on a five-grade system. Actually, the experiment subjects gave marks (from 1 to 5) to 9 coloured figures (3 figures $x 3$ figures) and 9 coloured three-dimensional shapes.

The new experiment did not confirm Kandinsky's hypothesis in terms of distribution of results, percentages of maximum marks and Cronbach's alpha coefficient.
\end{abstract}

Key words: figure-colour correlation, visual language, Kandinsky's experiment

\section{INTRODUCTION}

Looking for a universal visual language to surpass any cultural border, the modernists were concerned about the intrinsic meanings of shapes and colours. Also, the modernists were eager to discover a logical order, strictly objective, in aesthetics. The focus was on shapes and colours, but considered in isolation.

Wassily Kandinsky was the first modernist artist interested in the shape-colour interaction. He was also the first artist that created a totally abstract painting. Kandinsky had studied physiology of colour perception, psychiatry, chromotherapy and even occultism. As director of the first soviet institute of design (Inchuk in Moscow), he had the opportunity to run an ample questionnaire about correlation of colour with other perceptual elements. For example, a question was about coloursound association: 'What colour do you see when you are hearing a trumpet?' (Gage, 1995)

Later, Wassily Kandinsky was invited to teach at Bauhaus. Here, in 1923, he ran a much simpler questionnaire in the institute. The subjects were asked to fill three geometric flat shapes (a triangle, a square and a circle) with basic colours (yellow, red and blue). Three fields of questionnaire (profession, gender and nationality) were aimed to determine the subject's profile. About 1000 questionnaires were run (Gage, 1995). Kandinsky attained the academic agreement of Bauhaus teachers and students. He enounced the following correlation:

- triangle - yellow;

- $\quad$ square - red;

- circle - blue.

Two observations must be made: i) statistical data of the survey is lost (situation confirmed by Bauhaus Archives); ii) questionnaire was led (figure order is the same with colour order). Anyway, the "discovered" correlation produced great enthusiasm and several projects - a child cradle (Figure 1) and a mural painting, for example - were developed at Bauhaus. (Whitford, 1995)

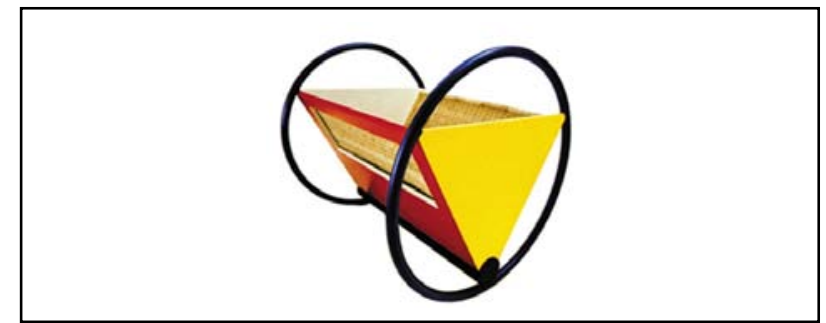

Fig. 1. Peter Keller - Cradle

Even unnoticed at that time, the child cradle points out the immense commercial value of the so-called discovery. If true, the discovery will lead to the design of successful products. A ball coloured in blue would sell far better than a violet ball.

At Bauhaus, Kandinsky was not the only one to analyse the shape-colour interaction. Before him, Johannes Itten had studied it and he had proposed an identical correlation based on his feeling. (Gage, 1995)

Johann Hantzsch carried out a scientific approach for confirmation of the above correlation. The results were published in his doctoral thesis in 1935 (Frieling, 1990). The subjects of Hantzsch's experiment were the pupils from the first to fourth grade of an art school. The pupils were asked to colour the elementary figures (triangle, square and circle) and, also, the associated three-dimensional shapes (pyramid, cube and sphere). The overall results of Hantzsch's experiment (as percentage of pupils that indicated the respective shape-colour combination) are displayed in Tables 1 and 2.

Even some authors considered significant the results of Hantzsch's experiment, it is obvious that they are irrelevant. In addition, the results were obtained from art pupils, which were supposed to have elementary knowledge of geometry and colour.

In 1990, Ellen Lupton (Lupton, 2000) ran again the Kandinsky's questionnaire and addressed it to industrial design professionals, teachers and critics. The opinions varied according to stylistic orientation of respondent - modernist or postmodernist. Two designers respected the questionnaire instructions and indicated the same correlation: triangle yellow, square - blue and circle - red. (Note that only triangle had the same colour like in Kandinsky's correlation.) But the majority of respondents filled all the figures with brown or with spots of different colours.

\begin{tabular}{|c|c|c|c|}
\hline Figure & Circle & Triangle & Square \\
\hline $\begin{array}{c}\text { Dominant } \\
\text { colour }\end{array}$ & Blue & Yellow & Red \\
\hline Percentage & $21 \%$ & $30 \%$ & $36 \%$ \\
\hline
\end{tabular}

Tab. 1. Results of Hantzsch's experiment for flat shapes

\begin{tabular}{|c|c|c|c|}
\hline Body & Sphere & Pyramid & Cube \\
\hline $\begin{array}{c}\text { Dominant } \\
\text { colour }\end{array}$ & Blue & Yellow & Red \\
\hline Percentage & $28 \%$ & $38 \%$ & $37 \%$ \\
\hline
\end{tabular}

Tab. 2. Results of Hantzsch's experiment for three-dimensional shapes 
Considering the inconsistencies indicated above, Andrei Dumitrescu organised an experiment in order to verify Kandinsky's hypothesis. The experiment was deployed in three phases (Dumitrescu, 2003):

1. repetition of Kandinsky's experiment with 3 shapes and 3 colours;

2. selection of the best combination shape-colour from the displayed set of the 6 possible combinations;

3. amplification of Kandinsky's experiment to 6 shapes and 6 colours.

The results of all three phases of the experiment indicated that Kandinsky's hypothesis was not confirmed by experimental data.

\section{EXPERIMENT DESIGN}

A new experiment was designed. In the new experiment, alongside with the flat shapes, there were introduced threedimensional shapes considering that these shapes are more "eloquent" to the viewer.

The new experiment had two phases. The first phase was focused on basic flat shapes (circle, triangle and square) and the second phase was focused on three-dimensional shapes (sphere, tetrahedron and cube).

Each flat and three-dimensional shape was physically produced from coloured cardboard (red, yellow and blue). Only the spheres were bought as coloured balls.

In each phase, all 9 shapes were shown to subjects who were asked to assess the appropriateness of shape-colour combination by marking each shape with a number from 1 to 5 . (" 1 " corresponds to the most inappropriate combination and " 5 " to the perfect combination.)

\section{EXPERIMENTAL RESULTS}

The experiment was carried-out personally by the author of the present paper with 615 subjects. The gender distribution of subjects was: 331 female and 284 male. All subjects were young (22-24 years old). None of the subjects had artistic training or knowledge about Kandinsky's experiment.

The raw results were recorded in a computer spreadsheet. For each combination shape-colour, there were calculated the following parameters:

- Mean;

- Standard deviation;

- Number of marks "5".

The mean distribution of correlation marks for flat shapes is presented in Table 3; the mean distribution of correlation marks for three-dimensional shapes - Table 4; the distribution of mark " 5 " for flat shapes - Table 5 and the distribution of mark " 5 " for three-dimensional shapes - Table 6. Note that in Tables 5 and 6, the percentages refer to all marks, not only to the "5" marks. (This is the reason why the sum is not $100 \%$.)

Examining the tables, it can be noticed a certain correlation, especially for square / cube - blue and circle / sphere - red (see numbers in bold). But colour yellow scored poorly for all shapes with one exception: the tetrahedron.

\begin{tabular}{|c|c|c|c|}
\hline & Circle & Triangle & Square \\
\hline Yellow & 3.19 & 3.07 & 2.54 \\
\hline Red & $\mathbf{3 . 9 0}$ & 3.50 & 3.15 \\
\hline Blue & 2.79 & 3.06 & $\mathbf{3 . 9 1}$ \\
\hline
\end{tabular}

Tab. 3. Mean distribution of correlation marks for flat shapes

\begin{tabular}{|c|c|c|c|}
\hline & Sphere & Tetrahedron & Cube \\
\hline Yellow & 3.37 & 3.45 & 2.55 \\
\hline Red & $\mathbf{3 . 8 4}$ & 3.33 & 3.14 \\
\hline Blue & 3.24 & 3.15 & $\mathbf{3 . 7 5}$ \\
\hline
\end{tabular}

Tab. 4. Mean distribution of correlation marks for threedimensional shapes

\begin{tabular}{|c|c|c|c|}
\hline & Circle & Triangle & Square \\
\hline Yellow & $25.7 \%$ & $17.9 \%$ & $9.11 \%$ \\
\hline Red & $\mathbf{3 6 . 3 \%}$ & $23.9 \%$ & $9.59 \%$ \\
\hline Blue & $7.15 \%$ & $13.8 \%$ & $\mathbf{4 0 . 3 \%}$ \\
\hline
\end{tabular}

Tab. 5. Distribution of mark " 5 ” for flat shapes

\begin{tabular}{|c|c|c|c|}
\hline & Sphere & Tetrahedron & Cube \\
\hline Yellow & $21.6 \%$ & $\mathbf{2 4 . 6 \%}$ & $8.46 \%$ \\
\hline Red & $\mathbf{3 1 . 4 \%}$ & $15.3 \%$ & $10.7 \%$ \\
\hline Blue & $17.4 \%$ & $13.5 \%$ & $\mathbf{3 0 . 4 \%}$ \\
\hline
\end{tabular}

Tab. 6. Distribution of mark "5" for three-dimensional shapes

If there were considered the maximum values of results, the correlation shape-colour appears as inconsistent. The maximum mark mean is 3.91 (compared with 5) and the maximum percentage is $40.3 \%$ (compared with obviously 100\%).

The standard deviations range was from 1.03 to $\mathbf{1 . 3 6}$. Considering that the marks' range is 4 units (= $5-1)$, the values of standard deviations are too high to indicate a strong tendency of results to gather close to the mean.

The experiment can be assessed using the Cronbach's Alpha coefficient (***, 2011). The Cronbach's alpha is a classic indicator used in psychometric assessment and this experiment is about psychological responses. Its formula is:

$$
\alpha=\frac{N}{N-1}\left(\frac{\sigma_{X}^{2}-\sum \sigma_{Y i}^{2}}{\sigma_{X}^{2}}\right)
$$

where $N$ is the number of items (shape-colour combinations); $\sigma_{x}^{2}$ - the variance of the observed total test scores, and $\sigma_{y}^{2}$ is the variance of item $i$.

After calculations, the Cronbach's alpha coefficient was determined:

$\alpha=0.39$

In order to indicate a successful experiment, the Cronbach's alpha should be higher than the critical value of $\mathbf{0 . 7 0}$. The experiment design was simple, clear and straightforward. Also, there are no grounds to suspect an unconstructive behaviour of subjects.

That means that the very basic idea of this experiment is faulty. The hypothesis of a strong correlation between shapes and colours proved wrong again.

\section{CONCLUSION}

The Kandinsky's hypothesis that the elementary geometric shapes are strongly related to certain basic colours was not confirmed (again) by the new experimental results.

Further more, the discovered weak correlation between square and blue and, respectively, circle and red is in opposition with postulated correlations indicated by Kandinsky: the square - red and the circle - blue.

\section{REFERENCES}

Dumitrescu, A. (2003). Study on Relationship between Elementary Geometric Figures and Basic Colours. POLITEHNICA University Scientific Bulletin, Series D, Vol. 65, No. 1-4, p77-90, ISSN 1454-2358

Frieling H. (1990). Gesetzt der Farbe. Goettlingen

Gage, J. (1995). Colour and Culture. Thames and Hudson, ISBN 978-0520222250, London

Lupton, E., (2000). The ABC's of [design]: The Bauhaus and Design Theory, Princeton Architectural Press, 9781878271426, Princeton

Whitford, F. (1995). Bauhaus. Thames and Hudson, 9780500201930, London

*** (2011) http://en.wikipedia.org/wiki/Cronbach\%27s_alpha, Accessed on: 2011-02-05 